Boletín de la Asociación de Geógrafos Españoles, 78, 302-328

ISSN: 0212-9426 elSSN: 2605-3322

Enlace DOI: http://dx.doi.org/10.21138/bage.2435

Cómo citar este trabajo: Guerrero Lladós, M., \& Burgueño, J. (2018). Disfunciones territoriales municipales en Catalunya. Boletín de la Asociación de Geógrafos Españoles, 78, 302-328. doi: http://dx.doi.org/10.21138/bage.2435

\title{
Disfunciones territoriales municipales en Catalunya
}

The boundary anomalies of the municipalities of Catalonia

\author{
Montse Guerrero Lladós \\ montse.guerrero@udl.cat \\ Jesús Burgueño \\ burgue@geosoc.udl.cat \\ Departament de Geografia i Sociologia \\ Universitat de Lleida (España)
}

\section{Resumen}

Los términos municipales pueden presentar anomalías o disfunciones en su configuración. Las más habituales son los enclaves y la superposición discordante de los límites respecto a los núcleos de población. El legislador autonómico puede corregir esas irregularidades, pero solo el territorio foral de Bizkaia ha reformado su planta municipal para suprimir todos los enclaves. Catalunya cuenta con la normativa más completa para racionalizar el mapa municipal, pero en la práctica la corrección de disfuncionalidades ha sido prácticamente nula.

Palabras clave: municipio; deslinde; disfunción; enclave; geografía política.

\begin{abstract}
Municipalities may have anomalies or dysfunctions in their shape. The most common are the enclaves and the overlapping of borders in localities. Spanish laws allow autonomous communities to undertake the correction of these irregularities, but only the province of Bizkaia has reformed its municipal layout in order to suppress all enclaves. Catalonia has the most complete legislation to rationalize its municipal map but, despite this, the correction of dysfunctionalities has been practically non-existent.
\end{abstract}

Key words: municipality; demarcation; dysfunction; enclave; Political Geography. 


\section{Introducción}

Los municipios son artefactos históricos. Sus límites se originaron, en la mayoría de casos, en la Edad Media. Por tanto, los términos jurisdiccionales se establecieron bajo un régimen señorial y en un contexto histórico, socioeconómico y de poblamiento, que poco o nada tiene que ver con la realidad geográfica actual. Por otra parte, una elevada fragmentación municipal comporta lógicamente más líneas de término, y por tanto más posibilidad que hoy día se generen situaciones conflictivas o disfuncionales, especialmente en zonas con alta intensidad de urbanización. Concretamente Cataluña cuenta con 948 municipios y unas 2876 líneas de término. ${ }^{1}$ El Institut Cartogràfic i Geològic de Catalunya (Massó \& Torres, 2009; Massó et al., 2011; Masdeu et al., 2015) ha restituido a escala 1:5.000 las líneas límite descritas en las actas de delimitación levantadas por los topógrafos del Instituto Geográfico entre los años 1910 y 1935, en el marco de los trabajos del Mapa Topográfico Nacional (Ticó \& García, 1994; Capdevila, 2005; Nadal \& Urteaga, 2012). Sin embargo, la concreción y actualización de dichos deslindes exige, en una segunda fase, la participación de los ayuntamientos implicados, lo cual ralentiza el proceso de verificación del trazado sobre el terreno; únicamente 249 municipios cuentan con todo su perímetro municipal actualizado. ${ }^{2}$

A diferencia del resto de CCAA, la legislación municipal catalana identifica, desde 1988, una serie de supuestos concretos de disfuncionalidad territorial en los límites municipales, y prevé un mecanismo legal específico para su corrección. Existe además una Comissió de Delimitació Territorial (CDT) como órgano de estudio, consulta y propuesta en las materias que afectan la revisión, determinación y modificación de los límites territoriales de los entes locales de Cataluña. ${ }^{3}$

Las dos principales disfunciones territoriales son los enclaves (fragmento de un término municipal totalmente inconexo) y la partición jurisdiccional de un núcleo de población (discordancia del límite con el área urbanizada). Estos problemas geopolíticos a menudo provocan incomodidades a la población afectada y son de difícil gestión por los ayuntamientos implicados. Está justificado, por tanto, que los geógrafos prestemos atención a estas cuestiones (Rueda et al., 1987; Oliveras, 1997; Burgueño \& Guerrero, 2014).

Aunque nuestro trabajo se centra en el caso catalán, primeramente convendrá situar la cuestión en el marco general español, tanto general o nacional como autonómico. Seguidamente nos centraremos en Cataluña; en primer lugar se explicará la definición de disfunción y el

12717 líneas descontadas las fronteras con Andorra y Francia, así como las líneas interautonómicas con Aragón y la Comunidad Valenciana. No se computa la línea de costa (Generalitat de Catalunya, 2018).

2 El estado de los trabajos, así como el mapa oficial de los municipios completados (Generalitat de Catalunya, 2018).

3 Decret 225/2002, de 27 d'agost, pel qual es regula la Comissió de Delimitació Territorial, reformado como D. 225/2002, de 27 de agosto. 
procedimiento de corrección establecido. A continuación se describen los diversos supuestos de disfunciones territoriales y se comenta un caso, frustrado, de mal uso de la normativa sobre disfunciones territoriales. También se apuntan unos posibles nuevos supuestos de disfunción, así como el caso especial en el que la totalidad del municipio forma un enclave. Finalmente se elaboran unas breves conclusiones.

\section{El marco legal estatal, autonómico y foral}

La legislación local española es parca en valoraciones sobre la configuración geográfica de los términos municipales. La Ley reguladora de las bases de régimen local (LRBRL, última actualización de 30/12/2013) no va más allá de afirmar que "El término municipal es el territorio en que el ayuntamiento ejerce sus competencias" (art. 12.1). En el Reglamento de población y demarcación territorial de las entidades locales (RD 1690/1986, de 11 de julio) se señala que "El término municipal está formado por territorios continuos, pero podrán mantenerse las situaciones de discontinuidad que estén reconocidas actualmente" (art. 1.3). Por tanto, la existencia de discontinuidades geográficas (es decir, enclaves) se apunta como un supuesto no deseable, implícitamente disfuncional, aunque no por ello se cuestionan los casos consolidados. En España existen del orden de 700 enclaves municipales (Burgueño \& Guerrero, 2014).

Del principio antedicho se deduce que no deberían crearse nuevos municipios cuyo territorio no fuera continuo, ni aprobarse fusiones o rectificaciones de términos que diesen lugar a nuevas discontinuidades. Efectivamente, aunque el Reglamento no insiere un precepto explícito sobre estos supuestos, el artículo 5 se refiere a la "fusión de municipios limítrofes a fin de constituir uno nuevo". Por otra parte, la alteración de límites ("La segregación de parte del territorio de un municipio para agregarlo a otro limítrofe") está justificada en dos situaciones, una muy concreta (la continuidad urbana) y otra muy genérica:

b) Cuando como consecuencia del desarrollo urbanístico se confundan sus núcleos urbanos, sin que constituyan solución de continuidad a este efecto los parques, jardines, paseos, avenidas, campos de deportes y zonas residenciales que pudieran existir entre aquéllos.

c) Cuando existan notorios motivos de necesidad o conveniencia económica o administrativa" (art. 7, que remite al 5).

Por tanto, implícitamente se considera que la partición jurisdiccional de los continuos urbanos es un problema.

A partir de estas directrices, las CCAA son plenamente competentes para incidir en el mapa municipal de su comunidad y, por ejemplo, proceder a corregir las discontinuidades existentes, si así lo estiman oportuno. La legislación autonómica referida al régimen local (Tabla 1) a menudo 
reproduce sin más las directrices de la LRBRL y del Reglamento de demarcación territorial. Sin embargo, en algunos casos la matización respecto del criterio general es notoria. La Ley de entidades locales de Castilla-La Mancha se desmarca del recelo ante los enclaves, pues en la relación de supuestos de alteración del término municipal se precisa que "La existencia de enclaves en otro término municipal no será motivo suficiente para que se produzca la alteración de términos municipales" (art. 3.3). Esta salvaguarda se intuye dirigida a los numerosos casos de pequeños municipios enclavados en el seno de un gran término (Cuenca, Montiel), del que antiguamente se segregaron.

También la normativa foral del territorio histórico de Álava contempla un supuesto que la legislación general descarta, ya que admite la ausencia de continuidad física en la fusión de municipios: "Sólo excepcionalmente y por razones de orden demográfico, geográfico, económico o administrativo debidamente justificadas, se podrán fusionar o agregar municipios que no sean limítrofes" (art. 7.2). Una puntualización que, por cierto, nos parece muy acertada, ya que no debería ser obstáculo para la unión, por ejemplo, de un pequeño pueblo a una gran ciudad el hecho que el terreno rústico que medie entre ambos pertenezca a un tercer municipio.

Andalucía amplía las especificaciones referidas a situaciones problemáticas de la delimitación municipal. El extenso artículo 20 del Reglamento de demarcación municipal señala cinco "supuestos justificadores de la alteración de términos municipales". ${ }^{4}$ Entre ellos se contempla la corrección de anomalías, pero este supuesto queda sujeto a un extraño dictamen que se confía al poder judicial: "d) Cuando sea necesario corregir anomalías que tuviesen su origen en una demarcación judicialmente declarada como arbitraria." También con motivo de unas indefinidas "causas sobrevenidas" (supuesto e): "Cuando haya que corregir anomalías originadas por causas sobrevenidas, siempre que no comporte perjuicios a los Municipios a los que afecta la alteración, y haya acuerdo entre los Municipios afectados." Ni estos enunciados, ni los que les preceden en el articulado facilitan gran cosa las alteraciones, más bien las dificultan, pues se introducen diversas referencias a la necesidad de compensaciones territoriales o bien se establecen requisitos muy exigentes; por ejemplo, si bien se admite la ampliación del término de una ciudad con el fin de ubicar determinados servicios, esto sólo será posible si se acredita la imposibilidad de establecer un régimen de mancomunidad con el ayuntamiento vecino.

La legislación local gallega, a imitación de la catalana (a la que nos referiremos luego), introduce la corrección de las disfunciones territoriales como una de las razones para proceder a una alteración de los términos municipales: "Os límites territoriais dos termos municipais poderán modificarse coa finalidade de axeitalos ás iniciativas de corrección de disfuncionalidades territoriais elaboradas pola

4 El Tribunal Superior de Justicia de Andalucía declaró nulo el art. 7 sobre continuidad territorial del término municipal y el art. 20 tiene también enmiendas. 
Comisión Galega de Delimitación Territorial. A modificación será acordada polo Consello da Xunta de Galicia, por proposta do conselleiro competente en materia de réxime local, logo da audiencia, polo prazo dun mes, dos municipios afectados, do informe da respectiva Deputación Provincial e do dictame do Consello Consultivo de Galicia" (art. 12.4).

También la Ley de administración local de La Rioja alude escuetamente a la necesidad de evitar disfunciones en los límites municipales: "La rectificación de límites territoriales para evitar disfuncionalidades se resolverá por acuerdo del Gobierno de La Rioja, previa audiencia a los municipios afectados y a la Administración General del Estado y dictamen del Consejo Consultivo de La Rioja" (art. 19). En sentido similar se pronuncia la normativa de Aragón: "Podrá efectuarse la simple rectificación de límites territoriales entre municipios, en los casos en que no resulte afectado un núcleo o asentamiento de población, para evitar disfuncionalidades en la prestación de servicios y conseguir una más eficiente administración del territorio" (art. 5 del Reglamento)".

La norma foral de Bizkaia de 1993 (actualmente superada) identificó claramente como problema la proliferación de enclaves territoriales, a los que dedicaba el título IV (art. 51 a 57) creando "el instrumento y cauce apropiado para posibilitar la corrección del grave problema de discontinuidad entre términos municipales que soportaba el Territorio Histórico de Bizkaia" (preámbulo de la NF 9/2012). De acuerdo con ese marco legal, se procedió a la supresión de los 42 enclaves y la racionalización del mapa municipal mediante la alteración de límites (Burgueño y Guerrero, 2014, 30).

En cambio, la legislación valenciana, si bien reitera el principio general que el término municipal deberá ser continuo, confía a los propios ayuntamientos la corrección de las disfunciones: "Els ajuntaments hauran d'adoptar les iniciatives necessàries per a eliminar qualsevol disfunció que en eixe sentit els afecte" (art. 5).

Además de Cataluña y Galicia, también Navarra cuenta con una Comisión de Delimitación Territorial como órgano de informe, estudio, consulta y propuesta en relación con las actuaciones referentes a alteración o revisión de límites territoriales (DF 278/1990, de 18 de octubre).

Por otra parte, Castilla-La Mancha es la comunidad que con mayor amplitud regula las compensaciones económicas pertinentes en caso de alteración de límites, estableciendo el principio que "El Municipio al que se le agregue una parte del término municipal de otro, deberá indemnizar económicamente a éste por un importe igual a 10 veces el valor actual de las cantidades dejadas de percibir por los impuestos sobre Bienes Inmuebles y Actividades Económicas correspondientes a los padrones de dichos impuestos en la porción a segregar para el ejercicio en el que se produzca la segregación" (art. 12). La legislación gallega recoge este mismo criterio: "El municipio al que se agregue una parte del término municipal de otro deberá indemnizar económicamente a éste en una cuantía igual a diez veces el valor actual de las cantidades dejadas de percibir por los impuestos 
sobre bienes inmuebles y actividades económicas que se devenguen en el territorio a segregar [...]" (art. 30.1). De manera similar, aunque sólo como opción, la Comunitat Valenciana afirma que: "La segregació de part d'un terme municipal per a la seua incorporació a un altre municipi, siga quina siga la seua causa, pot donar lloc a una indemnització pel municipi de destí a favor del municipi d'origen, sobre la base dels rendiments de la part segregada i durant un període de temps no superior a deu anys" (art. 16.2).

En conclusión, diversas CCAA reconocen - con énfasis variable- la existencia de disfunciones en los límites municipales, señaladamente en forma de territorios discontinuos o bien de continuos urbanos. En tres comunidades existen comisiones o consejos técnicos destinados al estudio y tutela de los procesos de delimitación municipal, con capacidad de iniciativa también en la corrección de las disfunciones. No obstante, únicamente Bizkaia ha pasado de la teoría a la práctica: al amparo de la legislación foral ha desarrollado una decidida política de racionalización del mapa municipal. Finalmente, tres comunidades abogan por indemnizar económicamente a los municipios que cedan territorio a otros de resultas de cualquier rectificación de límites.

La Tabla 1 resume a legislación municipal vigente desarrollada por las CCAA y los tres territorios forales vascos, a la que se refieren las citas jurídicas anteriores. Conviene observar que Cantabria y Extremadura no han legislado sobre esta materia, aunque sí lo han hecho acerca de las entidades locales menores.

\section{Tabla 1. Legislación municipal de las comunidades autónomas}

\section{Andalucía}

- Ley 5/2010, de 11 de junio, de autonomía local de Andalucía

- Decreto 185/2005, de 30 de agosto, Reglamento de demarcación municipal de Andalucía

Aragón

- Ley 7/1999, de 9 de abril, de administración local de Aragón

- Decreto 346/2002, de 19 de noviembre, Reglamento de territorio y población de entidades locales de Aragón

Asturias

- Ley 10/1986, de 7 de noviembre, reguladora de la demarcación territorial de los concejos del Principado de Asturias

\section{Illes Balears}

- Llei 20/2006, de 15 de desembre, municipal i de règim local de les Illes Balears

\section{Canarias}

- Ley 14/1990, de 26 de julio, de régimen jurídico de las administraciones públicas de Canarias $^{5}$

Castilla y León

- Ley 1/1998, de 4 de junio, de régimen local de Castilla y León

Castilla-La Mancha

- Ley 3/1991, de 4 de marzo, de entidades locales de Castilla-La Mancha

5 Esta Ley delega en los cabildos insulares, entre otras competencias, las demarcaciones territoriales y alteración de términos. 


\section{Tabla 1. Continuación}

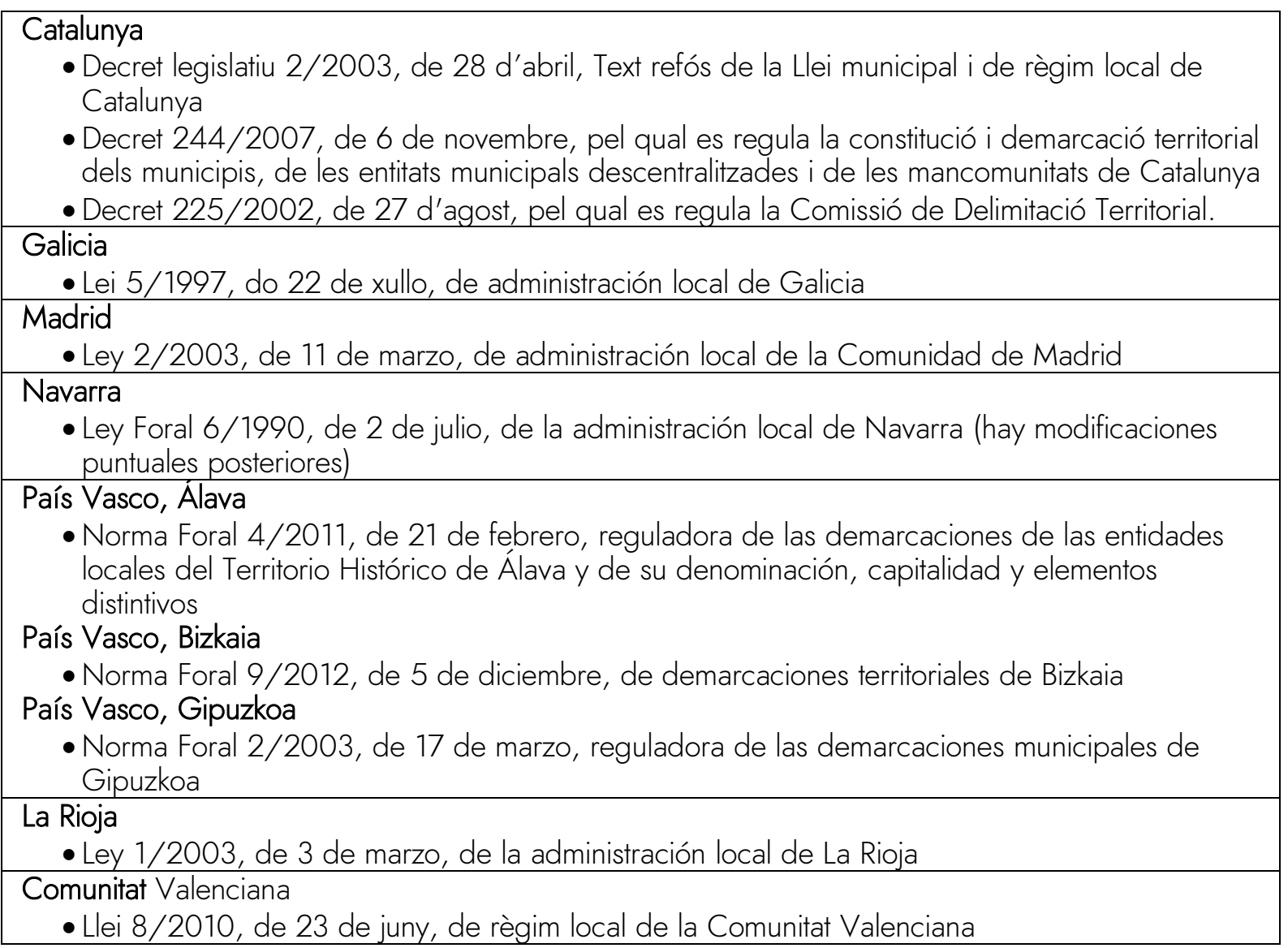

Fuente: elaboración propia

\section{Disfunciones en los límites municipales}

\subsection{Definición}

La Ley municipal catalana define el término municipal como "I'àmbit territorial on l'ajuntament exerceix les seves competències" y al tiempo afirma que su delimitación territorial: "ha d'atendre a les dimensions que li són més idònies per a l'exercici de les funcions públiques que l'ajuntament té encomanades, amb especial consideració dels criteris següents: la representació d'una col•lectivitat que té consciència com a tal, l'existència de valors històrics i tradicionals i la capacitat per a la gestió dels serveis públics que l'ajuntament té encomanats" (art. 11). Esta afirmación debería implicar una actitud activa: no cualquier delimitación consigue igualmente bien los objetivos expresados, y por tanto será lícito enmendar el perímetro de los municipios con el fin de obtener una demarcación y territorio (término municipal) más idónea.

Efectivamente, la legislación local catalana prevé una serie de supuestos de alteración de términos. El aspecto más novedoso en este sentido fue la introducción del concepto de disfunción territorial, primero en el Reglamento de demarcación territorial y población de los entes locales de Cataluña 
(D. 140/1988, de 24 de mayo) y actualmente en el Decreto 244/2007, de 6 de noviembre, por el cual se regula la constitución y la demarcación territorial de los municipios de Cataluña. ${ }^{6}$

El concepto disfunción territorial procede del Diagnòstic del mapa municipal de Catalunya, que en 1984 encargó la Direcció General d’Administració Local (DGAL) a los geógrafos Xavier Mateu e Isabel Rueda (Rueda et al., 1987). Es evidente que la tipología de disfunciones identificada en el Reglamento de 1988 (del que se deriva el actual) se inspiraba directamente en aquel estudio previo.

Los supuestos de disfunciones territoriales se enumeran en el artículo 21 del Decreto 244/2007; en la Figura 1 los ilustramos de forma esquemática.

Classes de disfuncionalitats territorials

Són disfuncionalitats territorials:

a) Els enclavaments.

b) Nucli, no capital de municipi, annex al nucli d'un municipi veí, formant un continu urbà.

c) Nucli, no capital del municipi, partit per un o més termes municipals.

d) Nucli ailllat de la seva capital i amb accés des d'un municipi veí.

e) Part d'un terme municipal o més fent falca dins un altre municipi.

f) Part d'un municipi aillat de la resta del municipi pel pas d'infraestructures o accidents geogràfics. $^{7}$

Figura 1. Supuestos de disfunción territorial municipal

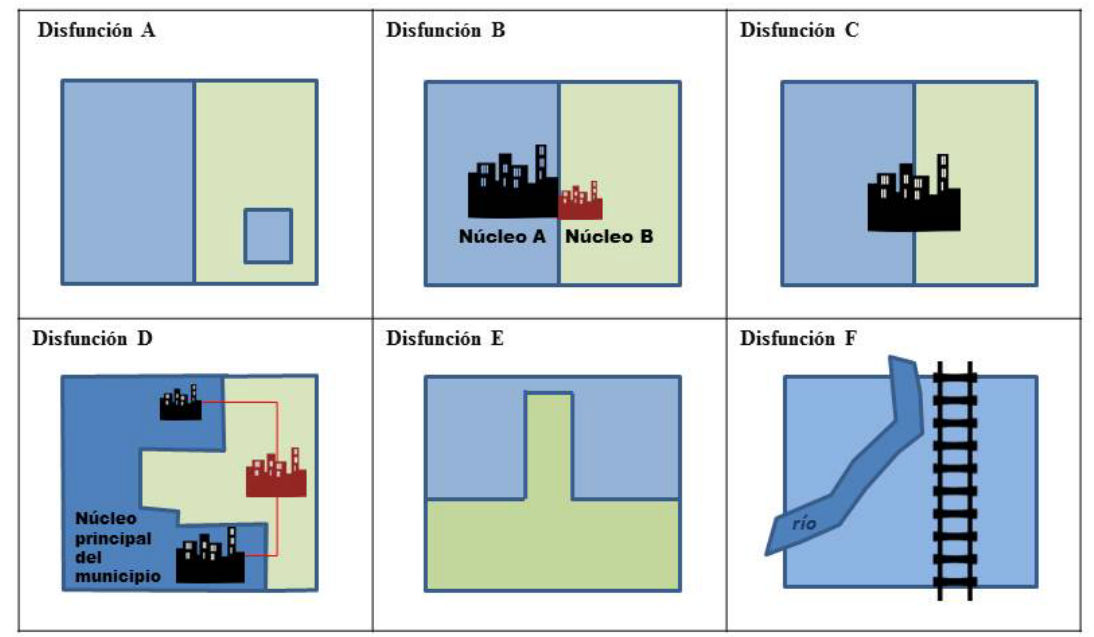

Fuente: elaboración propia

6 Este decreto se ha modificado recientemente (D. 209/2015, de 22 de septiembre), básicamente para agilizar y amparar legalmente las rectificaciones puntuales de la línea de término suscitadas en el actual proceso de concreción de la delimitación municipal (Masdeu et al., 2015).

7 La redacción de este último supuesto se ha modificado en la rectificación mencionada, haciéndolo casi incomprensible. Por eso preferimos presentar aquí la versión anterior. 


\subsection{Procedimiento de corrección}

El capítulo IV del Decreto de constitución y demarcación territorial de los municipios (art. 22) establece que la iniciativa de corrección de una disfunción corresponde exclusivamente a la CDT, ya sea por iniciativa propia o de su presidente, el conseller del Departament de Governació. No se trata, pues, de un procedimiento sujeto a la iniciativa particular de un municipio concreto. Cuando se trate de una propuesta de rectificación de límites acordada de mutuo acuerdo por dos municipios, el procedimiento a aplicar será el ordinario, de alteración de términos (art. 12 de la Ley municipal). Por tanto, aunque en la práctica, hablando en términos estrictamente geográficos, la corrección de una disfunción (como por ejemplo un enclave) pueda ser fruto de una alteración ordinaria (Figura 2), jurídicamente solo puede hablarse propiamente de una corrección de disfunción si esta es resultado de un procedimiento específico, que hasta ahora se ha demostrado de uso excepcional.

Resulta obligado, por tanto, describir brevemente la composición y finalidades de la CDT, creada en 1987, de acuerdo con las previsiones de la Ley municipal. Son funciones de la CDT informar sobre todos los expedientes de alteración de límites municipales; elaborar, a petición del Govern, estudios y propuestas de revisión del mapa municipal (fusiones...) y proponer modificaciones de límites (art. 27). En la actualidad cuenta con 8 representantes de la Generalitat (entre los cuales el conseller, el director general de Administración Local y el director del ICGC), otros 8 de las entidades municipalistas y únicamente 5 miembros sin sesgo político, uno de ellos del Colegio de Geógrafos. Con esta composición, está claro que es prácticamente inviable la aprobación de una resolución contraria a la opinión del Govern. Resulta igualmente claro que una iniciativa individual no tiene ninguna posibilidad de ser asumida por el conjunto de la CDT si no cuenta con el beneplácito de la conselleria.

La excepcionalidad de la tramitación de corrección de disfunciones se evidencia también en el hecho que el informe de los ayuntamientos afectados no se precisa con carácter previo (como en el caso de los de Urbanismo, consejo comarcal y diputación implicada), sino que se requiere a posteriori, como respuesta a la propuesta de la CDT. Como en todo tipo de procedimiento sobre delimitación territorial, también en la corrección de una disfunción es preceptivo el posterior informe de la Comissió Jurídica Assessora (CJA; art. 23 i 24). A la vista de todo ello, finalmente es el Govern quien debe adoptar la decisión de aprobar o no la corrección de la disfunción territorial (art. 25).

La Ley municipal (art. 28) prevé también la elaboración de un "mapa municipal" que exprese los límites territoriales de los términos municipales. Es en este punto donde la Ley se refiere explícitamente a la CDT y a las disfunciones territoriales, afirmando que "Aquests límits territorials dels termes municipals es poden rectificar per a adequar-los a les iniciatives de correcció de 
disfuncionalitats territorials elaborades per la Comissió de Delimitació Territorial" (art. 12.3). Por tanto, el legislador ponía en relación el mapa municipal definitivo con la corrección de las disfunciones. $^{8}$

Finalmente cabe añadir que el artículo 12.2 de la Ley municipal, en consonancia con la reiterada alusión de la legislación general al carácter limítrofe que deben presentar los municipios afectados por cualquier tipo de alteración, también afirma que "Cap alteració no pot donar lloc a un terme municipal discontinu". Esto, de alguna manera, también señala que no es deseable la existencia de municipios con territorios discontinuos.

\section{Tipología de disfunciones territoriales}

La lista de supuestos de disfunción no precisa el significado de los conceptos que emplea, lo cual deja cierto margen de interpretación y discrecionalidad al responsable de aplicar la Ley. En particular, tres de las seis disfunciones aluden a los núcleos de población, pero en ningún momento se concreta qué características debe tener un asentamiento humano para ser considerado como tal, por lo que debemos remitirnos a las definiciones del nomenclátor de población del INE.

Como ya hemos avanzado, el primer inventario de las principales disfunciones que presenta el mapa municipal catalán fue elaborado en 1984 (Rueda et al., 1988). También el llamado Informe Roca (Comissió d'experts, 2000) señalaba y proponía la forma de corregir buen número de disfunciones territoriales municipales. Finalmente, en su tesis doctoral, Montse Guerrero (2013) identifica 182 disfunciones de los términos municipales de la provincia de Lleida, ajustándose siempre a los supuestos identificados en la normativa legal. Los tres estudios mencionados permiten ilustrar la tipología de las disfunciones definidas por la legislación catalana. Posteriormente señalaremos otros posibles supuestos de disfunción que convendría tener en cuenta.

\subsection{Enclaves}

Un enclave municipal es una parte del término que no presenta continuidad territorial con el polígono (en la acepción SIG) o ámbito geográfico considerado principal del municipio, ya sea por su mayor superficie o por encontrarse en él la capital. Puede inserirse totalmente dentro de otro municipio o bien hallarse encastado entre varios términos. Los orígenes históricos pueden ser diversos: posesiones dispersas de un mismo señor feudal, pastos o bosques propiedad de un

8 Posiblemente ello explica que en la última rectificación del Reglamento que regula la tipología de disfunciones se haya alterado la redacción del supuesto f, de tal manera que el hecho descrito (la existencia de obstáculos geográficos) ahora solo puede aplicarse a infraestructuras realizadas con posterioridad a la aprobación del mapa del perímetro municipal revisado. Esta alambicada argucia pretende blindar la realización de las lógicas mínimas enmiendas que surgen durante el proceso de revisión y actualización de límites (art. 30.1), diferenciando netamente la operación de oficio respecto de la excepcional corrección de una disfuncionalidad. Se quería evitar (quizás con un exceso de suspicacia) que un pequeño desplazamiento de mojones se interpretara como la corrección encubierta de una disfunción y que alguna instancia jurídica superior declarase nulo todo el procedimiento. 
determinado pueblo, ${ }^{9}$ etc. Cuando el enclave contiene un núcleo de población, generalmente se trata de una adscripción municipal relativamente reciente, fruto de un proceso de agregación de municipios, como el que se llevó a cabo con la Ley de ayuntamientos de 1845 (Burgueño \& Lasso, 2001; Burgueño \& Gras, 2014).

Los enclaves son las disfunciones territoriales más llamativas, y por eso han merecido cierta atención, aunque generalmente a escala estatal o provincial (Carnicer, 1995), sin descender al nivel municipal (Gallés, 1985). Son el único tipo de disfunción territorial del que existe un recuento oficial: el ICGC contabiliza 77, ${ }^{10}$ nosotros elevamos esta cifra a 81, por ejemplo contabilizando la pertenencia de la iglesia de Correà a Montmajor, tal como acredita el Catastro (Figura 2). ${ }^{11}$

Figura 2. Sant Martí de Correà, enclave de Montmajor en l'Espunyola (Berguedà)

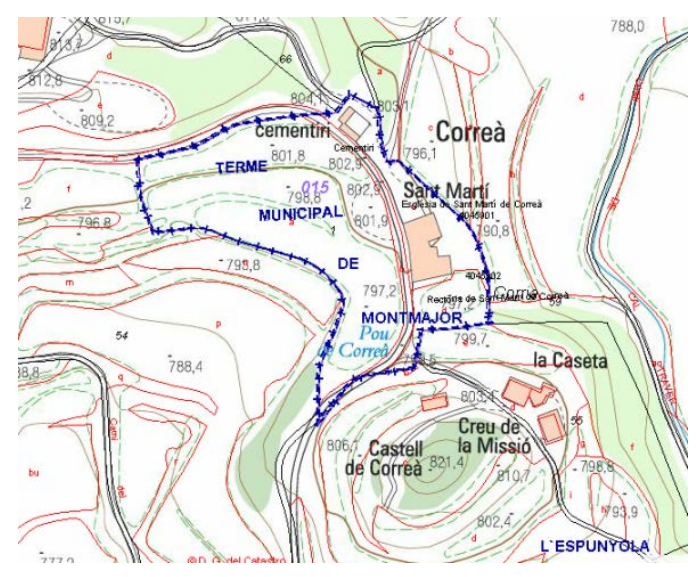

Fuente: ICGC (2018) y Catastro

Desde que Cataluña recuperó el autogobierno únicamente se han suprimido dos enclaves: el denominado Perers que el término de Olius (Solsonès) tenía situado en el de Llobera (D. 190/1990, de 30 de julio) y, muy recientemente, el más pequeño de los dos que hasta ahora tenía el municipio de Barcelona en la sierra de Collserola (D. 19/2017, de 21 de marzo), mediante un intercambio de territorio con Sant Feliu de Llobregat. Ambas rectificaciones se han llevado a

9 De este tipo son los numerosos existentes en el Pallars Sobirà, cuyo mapa de términos tradicionales hemos cartografiado últimamente (Burgueño \& Mòdol, 2016).

10 Una enumeración detallada en: Llista d'enclavaments a Catalunya (n.d.). In Wikipedia. Retrieved from https://ca.wikipedia.org/wiki/Llista d'enclavaments a Catalunya

11 Debe descontarse uno de los enclaves de Barcelona en la sierra de Collserola. Es preciso añadir el que el ICGC ha cartografiado recientemente y que además tiene el carácter de enclave provincial, como ya señalara en su día Ramón Carnicer (1995); se trata de las ruinas de una masía inmediata al monasterio de Sant Pere de Graudescales que pertenece al término de Montmajor (Berguedà); sin duda se trata del enclave municipal más pequeño de Cataluña, con apenas 228 m2. Además, cartográficamente es posible distinguir otro enclave más, que equivocadamente se computa unido al de Mont-rodon (Tona, Osona) cuando en realidad constituye un polígono distinto, aunque históricamente pertenecía a la misma jurisdicción señorial. Hay otros tres enclaves que no están cartografiados pero que sí figuran (o constaban cuando estaban habitados) en el nomenclátor de población: el pueblo de Romadriu, que pertenece a Llavorsí (Pallars Sobirà) y no a Farrera; la aldea de L'Artiga, de El Pont de Suert (Alta Ribagorça) pero enclavada en Vilaller; y Correà (Figura 2). 
cabo, no por iniciativa de la Generalitat mediante un expediente de corrección de disfunción territorial, sino por acuerdo de los entes interesados y por el procedimiento ordinario.

La Generalitat sí quiso, en 2002, mediante una corrección de disfunción territorial, suprimir el enclave de Les Rovires de Baix, pertenencia del término de les Llosses (Ripollès, provincia de Girona) enclavado en Borredà (Berguedà, provincia de Barcelona), pero el Tribunal Superior de Justícia de Catalunya (TSJC), a instancias del Ministerio de Administraciones Públicas, tuvo que recordar (!), en sentencia n 937/2005, que "cualquier alteración de los límites provinciales habrá de ser aprobada por las Cortes Generales mediante ley orgánica" (art. 141.1 CE). ${ }^{12}$

\subsection{Núcleo, no capital de municipio, anexo al núcleo de un municipio vecino formando un continuo urbano}

Este es el primero de los dos supuestos de la norma que alude a núcleos de población situados en una línea de término. Es dudoso que sea preciso diferenciar ambas situaciones, puesto que se podrían agrupar simplemente en la categoría de "límite municipal superpuesto a un continuo urbano". Esta modalidad se refiere concretamente a dos núcleos identificados por nombres distintos, pese a configurar una misma realidad urbanística. Tal supuesto puede darse tanto cuando uno de los núcleos en contacto tiene una dimensión claramente superior (puede ser capital de municipio), como cuando ambos son de un tamaño similar. El primer caso siempre podrá considerarse una disfunción, pero el segundo posiblemente tendrá excepciones: dos urbanizaciones de términos limítrofes pueden ser contiguas pero no presentar problemas de inserción en los respectivos municipios ni configurar realmente una unidad local cohesionada y relativamente autónoma.

La existencia de un límite administrativo discordante con la realidad urbana suele tener un origen histórico. Es frecuente que en el momento fundacional de las jurisdicciones medievales se adoptara como límite de término un camino, en las inmediaciones del cual, con el tiempo, se ubicó una masía y quizás también un hostal, y finalmente, siglos después, acabó configurándose un núcleo de población en forma de arrabal o de calle, que fácilmente podía llegar a tener una acera situada en cada término municipal.

Algunas de las modificaciones parciales de términos municipales efectuadas por la Generalitat obedecen a esta situación de continuidad urbana, si bien ninguna de ellas se tramitó precisamente como una corrección de disfunción territorial:

12 Art. 3.2 de la Ley de Régimen Local vigente entonces, y que en la LRBRL vigente desde 2004 ha dado lugar al art. 13.1: "La creación o supresión de municipios, así como la alteración de términos municipales, se regularán por la legislación de las comunidades autónomas sobre régimen local, sin que la alteración de términos municipales pueda suponer, en ningún caso, modificación de los límites provinciales". 
- Agregación de la Planeta (Aiguamúrcia) a El Pont d’Armentera (Alt Camp), 1981.

- Agregación a Santa Eugènia de Berga (Osona) del arrabal que pertenecía a Taradell, 1991.

- Agregación a Olost (Osona) del arrabal que pertenecía a Oristà, 1992.

- Agregación a Sant Martí Sesgueioles (Anoia) de las casas inmediatas que pertenecían a Pujalt, 1992.

- Agregación a Calldetenes (Osona) del sector inmediato que pertenecía a Santa Eugènia de Berga, 1995.

- Agregación a La Torre de Fontaubella (Priorat) de un barrio que pertenecía a Pradell de la Teixeta, 1996.

- Agregación a Sant Pere de Riudebitlles (Alt Penedès) de un barrio que pertenecía a Torrelavit, 1999.

- Agregación a Balenyà (Osona) de un pequeño sector inmediato a la capital de ese municipio (els Hostalets de Balenyà) que pertenecía a Seva, 1999.

- Agregación a Sant Julià de Vilatorta (Osona) de un barrio que pertenecía a Calldetenes, 2000.

- Agregación a Puigdàlber (Alt Penedès) de un barrio que pertenecía a El Pla del Penedès, 2002.

Como puede observarse, no ha habido nuevas alteraciones en los últimos 15 años.

\subsection{Núcleo, no capital de municipio, partido por uno o más términos municipales}

Esta segunda modalidad de discordancia entre el límite jurisdiccional y la realidad urbana excluye el caso de una capital de municipio. Supone la percepción de que en realidad existe un solo núcleo, lo cual -añadimos nosotros- está fuera de duda cuando los diversos fragmentos comparten topónimo. Este supuesto es aplicable tanto en un caso de distribución equilibrada del caserío entre los términos municipales implicados, como en un supuesto en que uno de los municipios contenga una porción muy mayoritaria del pueblo en cuestión, de tal manera que solo exista cierta extensión o desbordamiento del crecimiento urbano en el término vecino.

Esta situación explica alguna fusión municipal pretérita, como las de Vallvidrera y Sarrià (hoy Barcelona) en 1888, Lavit i Terrassola (Alt Penedès) en 1918 para constituir Torrelavit (topónimo también aglutinado) o La Manresana y Portell (Segarra) en 1940 para formar Sant Ramon. También este tipo de disfunción justifica alguna segregación municipal como la de Vilanova del Vallès (1983), localidad anteriormente repartida entre Montornès y La Roca del Vallès, o la creación del micromunicipio de Badia del Vallès, en 1994, antiguo polígono de viviendas cuyas edificaciones pertenecían a los términos de Barberà y Cerdanyola del Vallès. Algunas rectificaciones parciales de términos municipales, efectuadas siempre en urbanizaciones, encajan con este supuesto de disfuncionalidad territorial, si bien el procedimiento administrativo seguido ha sido el ordinario en todos los casos, a partir de la iniciativa de alguno de los ayuntamientos implicados y por mutuo acuerdo. Las más relevantes son: 
- Agregación de la parte de la urbanización de El Solà del Boix que pertenecía a Castellcir a Sant Quirze Safaja (Moianès), 1998.

- Agregación de la porción de la urbanización de L'Abellar que pertenecía a Albatàrrec a Montoliu de Lleida (Segrià), 2002.

- Agregación de la pequeña parte de la urbanización de El Serrat de Castellnou que pertenecía a Santpedor a Castellnou de Bages, 2011.

- Agregación de una pequeña parte de la urbanización de Castellar d'Índies que pertenecía a Tordera a Sant Cebrià de Vallalta (Maresme), 2014.

A este supuesto responde, además, la única auténtica corrección de disfuncionalidad territorial efectuada por la Generalitat. A raíz de la ubicación de una estación de ferrocarril en la línea de Barcelona a Vic (1870) se formó un pequeño núcleo urbano, hoy conocido como Sant Miquel de Balenyà, situado a caballo de tres términos municipales de la comarca de Osona. En la década de 1990 contaba con unos 800 habitantes y reclamó su segregación como municipio independiente. El Govern de la Generalitat denegó la petición en 1993 y buscó una alternativa: la agregación al municipio que comprendía la mayor parte del núcleo (Seva) de los sectores que pertenecían a Balenyà y El Brull (D. 157/1995, de 16 de mayo). Cabe añadir que en 2014 este núcleo adquirió el rango de entidad municipal descentralizada (EMD), equivalente a la entidad local menor general.

Actualmente se encuentra en trámite la resolución un contencioso similar: La Beguda Alta, núcleo de población repartido en porciones similares entre los municipios de Masquefa (Anoia), Sant Esteve Sesrovires (Baix Llobregat) y Sant Llorenç d'Hortons (Alt Penedès). La CDT ha recomendado la agregación del núcleo a Masquefa, de acuerdo con el parecer del 76\% de su población (encuesta en: Servei CT de Cartografia i SIG, 2016)

Los políticos parecen entender que la Generalitat únicamente debe levantar acta de aquello que los ayuntamientos acuerden entre sí, es decir: aceptar solo alteraciones de término y no impulsar la corrección de ninguna disfunción. Sin embargo, la legislación catalana no prevé en absoluto que la Generalitat sea mera espectadora de la realidad territorial municipal, sino agente de cambio mediante un procedimiento legal de corrección de las disfunciones más flagrantes. Tanto es así que el decreto que regula la CDT, además de confiarle la iniciativa (propia o a petición del conseller) en la corrección de las disfuncionalidades (art. 16), le insta también a pronunciarse de oficio, como mínimo cada 10 años, sobre la actualización del mapa municipal y formular las propuestas de modificación que considere pertinentes (art. 13.3). Esto nunca se ha cumplido.

\subsection{Núcleo aislado de su capital y con acceso desde otro municipio vecino}

Este tipo de disfunción se refiere a aquellos núcleos que, aunque no tengan continuidad urbanística con una localidad adscrita a un municipio colindante, básicamente se relacionan con la capital vecina por razón de la estructura del relieve y, principalmente, de las comunicaciones existentes. 
Puede, incluso, que la ruta más práctica (quizás la única posible) para dirigirse en coche a su capital administrativa atraviese pueblos vecinos ajenos al propio municipio. No es raro que, en estos casos, la carretera que constituye el principal acceso al pueblo sufra cierta dejación, al transcurrir por un municipio ajeno sin dar servicio a la población del mismo.

Este tipo de disfunción lógicamente es más frecuente en municipios compuestos (formados por diversos núcleos de población), generalmente como resultado de una fusión o agregación de antiguos municipios. Cuando esto es así, se evidencia que la agregación efectuada posiblemente no fue la más idónea desde el punto de vista geográfico. En la provincia de Lleida esta es la modalidad de disfunción más frecuente, posiblemente porque es el territorio que ha sufrido más agregaciones (los 732 municipios existentes en 1842 se han reducido a 231) y porque muchas de ellas fueron poco meditadas.

Por ejemplo, desde el pueblo de Pallerols (Segarra), antiguo municipio agregado a Talavera en 1847, para acudir a su ayuntamiento (situado a 8 km) resulta obligado pasar por el inmediato núcleo de Sant Antolí i Vilanova (a 1 km), que es la capital del municipio de Ribera d'Ondara.

Solo una de las alteraciones de términos ordinarias efectuadas en las últimas décadas responde a esta situación disfuncional: ${ }^{13}$ el núcleo de Valls de Torroella, del municipio de Navàs (Bages), se hallaba a 24 km de su capital, pasando por cuatro términos municipales. En 2000 se incorporó al municipio vecino de Sant Mateu de Bages, aunque la solución únicamente suaviza el problema, ya que para acceder a su nueva capital sigue siendo preciso transitar por otros dos municipios.

En el vocabulario geopolítico, en ocasiones esta situación geográfica se denomina perienclave, aunque es un término de uso muy restringido. El centro de terminología catalán Termcat lo ha adaptado como penenclavament y lo define como: "Territori que no depèn administrativament de la demarcació dintre de la qual està majoritàriament situat sinó d'una altra, respecte de la qual presenta una continuïtat física o d'accés mínima." Wikipedia emplea la forma pene-enclave: "A pene-enclave is a part of the territory of one country that can be approached conveniently -in particular by wheeled traffic- only through the territory of another country. Pene-enclaves are also called functional enclaves or practical enclaves." Ambas fuentes ponen como ejemplo la localidad de Os de Civís (municipio de Les Valls de Valira, Alt Urgell) únicamente accesible para el tránsito rodado convencional desde Andorra.

\subsection{Parte de un término municipal o más haciendo cuña en otro municipio}

Este supuesto se añadió en la revisión del Reglamento de 2007, pues en el original de 1988 no figuraba. La redacción es un tanto extraña, porque no es fácil que una cuña pueda ser debida a

13 El paso de Taravaus, de Navata a Vilanant (Alt Empordà), en 1996, fue una opción propia que no se debía a incomunicación con el ayuntamiento al cual se había agregado en 1969. 
más de un municipio, y en cambio sí es normal que el extremo de un término se introduzca entre dos términos municipales, quedando esta situación excluida como disfuncionalidad atendiendo a la literalidad del precepto.

El sentido geopolítico que se ha querido dar a falca (cuña, en catalán) presenta un significado próximo al expresivo término inglés panhandle, generalmente adaptado al castellano simplemente como "saliente". ${ }^{14}$ Esta disfuncionalidad es la más subjetiva de todas, por cuanto es difícil concretar cuándo puede considerarse que un término se insiere de forma profunda e incómoda en el seno de otro municipio. Además, no se trata únicamente de una cuestión de dimensión, sino del uso del suelo: un saliente de terreno rústico, deshabitado y alejado de cualquier núcleo de población realmente no supondrá una disfunción relevante. En el estudio de las disfunciones municipales en la provincia de Lleida (Guerrero, 2013) se consideró cuña la penetración de un término municipal en el seno de un municipio vecino cuando esta superaba una longitud de $2 \mathrm{~km}$. De esta forma se contabilizaron únicamente 7 casos, y aun así, valorados con detalle, no parecen disfuncionalidades de importancia.

Pero como decimos, este supuesto presenta el inconveniente de su aparente inaplicabilidad en el caso de cuñas inseridas entre dos o más municipios, como es el caso de algunas de las más evidentes irregularidades del mapa municipal catalán. Por ejemplo, la partida meridional del término de Juneda (L'Aranyó) se alarga hacia el sur entre otros tres municipios (Les Borges Blanques, Castelldans y Cervià de les Garrigues), dibujando una especie de mango de martillo (Figura 3). Sí serían pequeñas cuñas inseridas en un solo municipio los salientes que entrelazan los términos municipales de Bellmunt d'Urgell y de Penelles (Noguera).

Figura 3. Municipios de Bellmunt d'Urgell y Penelles (izquierda) y Juneda (derecha)

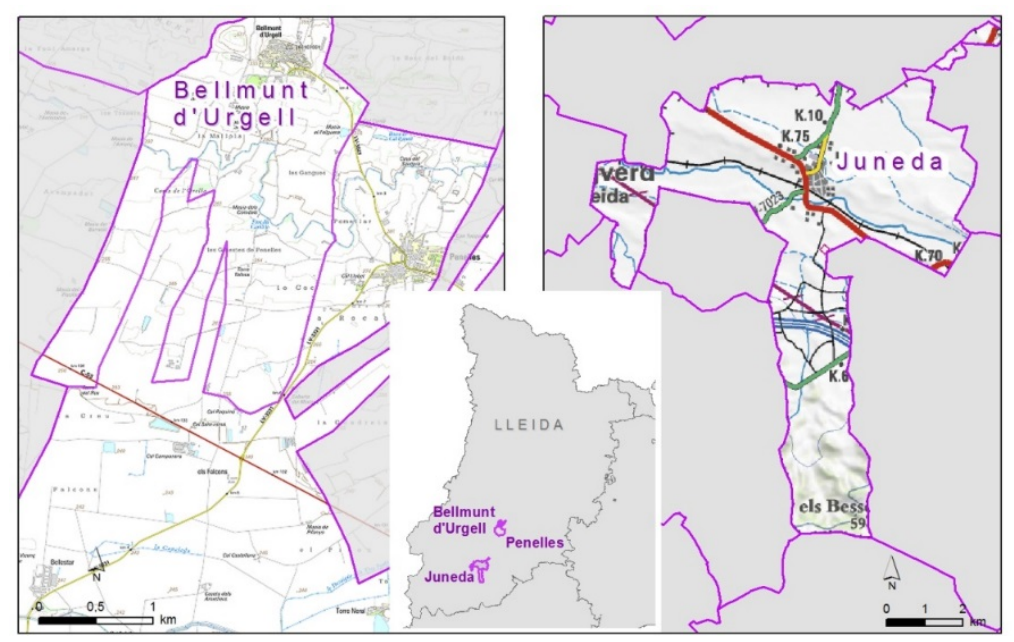

Fuente: elaboración propia a partir de la base cartográfica ICGC (2017)

14 Alguna definición de "periclave" encaja también con el concepto de cuña o apéndice (López Trigal, 2013, p. 100). 
En definitiva, el concepto de cuña territorial no nos parece justificado como descripción de una disfunción territorial. Sería más apropiada una redacción que, aunque aparentemente fuera más genérica, permitiera un uso más flexible y operativo del supuesto. Algo así como: "Irregularidad manifiesta en el trazado de un límite municipal: excentricidad, saliente acusado o sinuosidad extrema".

En las últimas décadas únicamente se ha rectificado (nuevamente por el procedimiento de alteración ordinaria) un saliente: La Clau de Mura, que en 1994 pasó de Mura a El Pont de Vilomara i Rocafort (Bages). Este sector presentaba la disfunción añadida de comprender una urbanización (El Marquet) que formaba continuo urbano con el núcleo de El Pont de Vilomara.

\section{Figura 4. Municipios de Puigverd d'Agramunt y Tornabous}

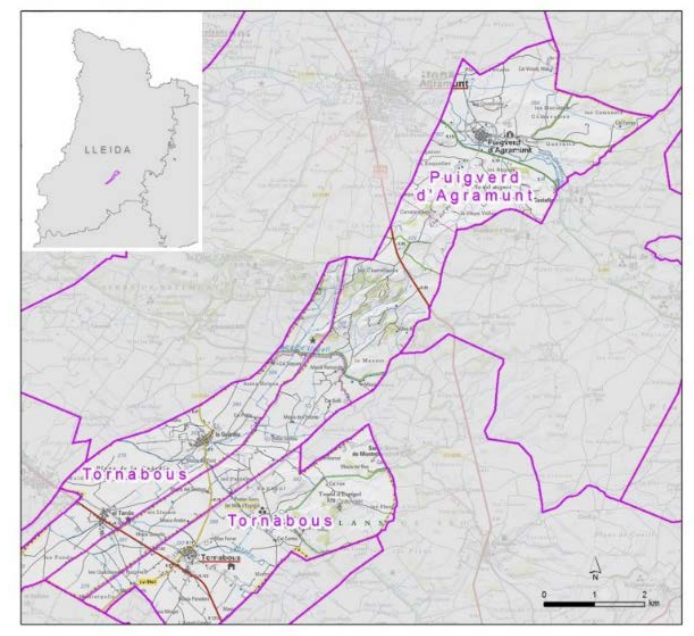

Fuente: elaboración propia a partir de la base cartográfica ICGC (2017)

En realidad hubo también otra tentativa en el mismo sentido: la agregación del largo apéndice meridional del término municipal de Puigverd d'Agramunt (Urgell) a Tornabous, en 1999 (Figura 4). Esta rectificación solventaba además otra disfunción: la división del término de Tornabous en dos sectores: el de la capital con el enclave que comprende los pueblos anejos de La Guàrdia y El Tarròs. El problema en este caso se debió precisamente al procedimiento seguido, el ordinario de alteración parcial, y no el que realmente correspondía, de corrección de disfuncionalidad territorial. Dado que la iniciativa fue adoptada por el Ayuntamiento de Tornabous y que el de Puigverd siempre se opuso al cambio, aunque la Generalitat apoyó la propuesta, el TSJC declaró nulo todo el proceso (resolución n 598/2004) por estimar, entre otros defectos de forma, que el acuerdo del consistorio de Tornabous: "fue adoptado con la intervención de diversos concejales en quienes concurría motivo de abstención por la existencia de un interés directo, derivado de su condición de propietarios o familiares de propietarios de una parte significativa de los terrenos afectados por el expediente." Difícilmente podría constituirse un Ayuntamiento en Tornabous en el que ninguno de los concejales tuviera familiares con tierras en ese territorio inmediato. La solución del problema 
consiste simplemente en ceder la iniciativa a la CDT, tal como está previsto en la corrección de disfuncionalidades territoriales.

\subsection{Parte de un municipio aislado del resto del municipio por el paso de infraestructuras o por accidentes geográficos}

La trayectoria de este epígrafe ha sido la más accidentada en el elenco de disfuncionalidades territoriales. En la redacción inicial (art. 41.3, D. 140/1988) este supuesto se refería únicamente a vías de comunicación: "Disfuncionalitats causades pel pas de grans infrastructures, ailllament de part d'un municipi per causa de les vies fèrries, les autopistes i els aeroports". La siguiente versión (art. 21, D. 244/2007) es la que encabeza este apartado e incorpora los accidentes geográficos. Aunque no se especifican, pueden identificarse básicamente cinco tipos de barreras físicas derivadas de las formas del relieve: sierras, despeñaderos, grandes ríos, barrancos encajados y lagos o pantanos. Claro está que todos estos elementos pueden ser transitados mediante carreteras, túneles, puentes..., de modo que resultaría más significativa la alusión a los accidentes geográficos complementándola con la ausencia de vías de comunicación que permitan superarlos.

En la provincia de Lleida hemos detectado 33 núcleos de población aislados de su respectiva capital municipal por la interposición de accidentes geográficos, principalmente ríos y embalses; ninguno, en cambio, aislado por el paso de una gran vía de comunicación (autopista o ferrocarril). Por ejemplo, el núcleo de L'Ametlla del Montsec no tiene enlace interno por carretera con su capital (Camarasa, localidad a $30 \mathrm{~km}$ ) debido a la interposición del embalse homónimo, mientras que el pueblo vecino, Àger, se encuentra a sólo 9 km. Evidentemente si ampliamos la identificación de este supuesto a ámbitos despoblados o con población exclusivamente dispersa, la relación de disfuncionalidades sería muy superior, pero también sería discutible la relevancia de la rectificación.

Ninguna de las alteraciones de la delimitación municipal catalana efectuadas en las últimas décadas obedece a la interposición de un accidente, ya sea natural o de creación humana. ${ }^{15}$

15 En la última modificación del Reglamento (D. 209/2015, de 22 de septiembre) la frase del supuesto f se alarga y pasa a ser: "Part d'un municipi aillat de la resta del municipi pel pas d'infraestructures o accidents geogràfics o per la modificació antròpica del territori, sempre que l'aïllament esdevingui amb posterioritat a l'aprovació del mapa del municipi afectat". Al margen de las razones de este cambio, no del todo claras pero ya comentadas (nota 15) lo cierto es que el significado de la frase, el alcance del supuesto, se ha oscurecido hasta resultar incomprensible. Si bien por un lado se añade la críptica expresión "modificación antrópica", que suponemos alude simplemente a la forma concreta de extensión de la urbanización (viales y construcciones), por otra parte se señala una extraña fecha de caducidad en los obstáculos geográficos de cualquier tipo (físicos y humanos). Un obstáculo geográfico natural (río, estrecho, despeñadero o sierra) siempre es previo a cualquier revisión de límites municipales (salvo modificación en el curso de un río, circunstancia hoy día muy rara en nuestro país, gracias a la regulación hidrológica), y por tanto es absurdo condicionar una rectificación a que el motivo de la disfunción sea de aparición reciente. De alguna manera esta nueva redacción absuelve las disfunciones previas a la aprobación del mapa municipal definitivo (es decir, la revisión-concreción de límites que la Generalitat tiene en marcha). Así, una autovía que existía antes de la revisión automáticamente deja de constituir una barrera. Solo si el obstáculo aparece posteriormente podría dar lugar a enmienda. El resultado final de la rectificación es, por tanto, nefasto, porque prácticamente deja sin efecto el supuesto f. Más habría valido eliminar este subapartado de la relación de disfuncionalidades. 


\section{Otros posibles supuestos de disfuncionalidad territorial}

\subsection{Entidad vs. núcleo de población}

La normativa catalana enfatiza la existencia de un núcleo de población para definir diversas disfunciones. Por eso fracasó un intento de aplicación fraudulenta de la norma al caso de una agrupación arbitraria de masías (con un territorio de $25 \mathrm{~km}^{2}$ ) que pretendía pasar de los municipios de Biosca y Torà (Segarra) al de Llobera (Solsonès). En su dictamen 416/09, la CJA dio la razón al recurso interpuesto por el Ayuntamiento de Torà (Servei CT de Cartografia i SIG, 2009), "en el sentit de considerar que no hi concorren els pressupòsits materials previstos en l'ordenament, i en concret els previstos en les lletres d) i f) de l'article 21 de l'RCDEM al•legats per la Comissió de Delimitació Territorial". ${ }^{16}$

No obstante, cuando se trata de una entidad de población (es decir, un territorio con personalidad histórica, a menudo de origen parroquial) formada exclusivamente por masías, carente de núcleo urbano -una situación frecuente en la Cataluña oriental y generalizada en las comunidades atlánticas peninsulares - también debería entenderse que nos encontramos antes una unidad geográfica cohesionada, a menudo con una historia municipal independiente, merecedora de ser considerada como un sujeto geopolíitico, al cual es legítimo asegurar un encaje idóneo en el mapa municipal. Más concretamente, el supuesto $d$, referido a la falta de acceso directo a la capital municipal, debería aplicarse tanto a núcleos como a entidades de población.

Por ejemplo, la entidad de población de Múnter (48 h), una parroquia y jurisdicción que fue independiente hasta 1836, se halla a 8,5 km por carretera de su capital municipal, Muntanyola (Osona), a la cual debe acceder a través de otros municipios salvando $200 \mathrm{~m}$ de desnivel, cuando el municipio vecino, Malla, tiene su ayuntamiento a solo 5,3 km en terreno llano y bien comunicado (la Plana de Vic) y se trata de una localidad formada igualmente por masías (267 h) y con el mismo perfil socioeconómico agrario (la mayoría de la población de Muntanyola reside en urbanizaciones). Recientemente Malla ha iniciado los trámites para solicitar una rectificación de la línea de término y acoger la entidad de Múnter.

\subsection{Continuo urbano}

Este concepto figuraba en la primera redacción del Reglamento, en 1988 (art. 41.4); en la actual, la continuidad urbana se supedita a la presencia de un núcleo diferenciado. En principio parece una buena idea remarcar que el problema fundamental se encuentra en los casos de partición de

16 Rebés i Solé, Josep-Enric (2009). Expediente de corrección de disfuncionalidades territoriales de los municipios de Biosca, Torà (Segarra) y Llobera (Solsonès) [DICTAMEN: 416/09, de 26 de noviembre]. Retrieved from hitp://portaldogc.gencat.cat/utilsEADOP/PDF/noDOGC/1416118.pdf

La fijación de la DGAL por el contencioso es notable, pues ya anteriormente la CJA había desautorizado la segregación (D. 20/1995, de 25 de enero). 
áreas urbanizadas que funcionan como un mismo caserío o núcleo. Se evita así considerar el caso de contacto urbano entre dos núcleos autónomos y potentes, entre los cuales ya no existe discontinuidad física a causa de la urbanización generalizada del territorio, situación especialmente frecuente en el entorno metropolitano. Cuando todo el territorio está urbanizado no tiene mucho sentido desplazar significativamente la línea del límite administrativo.

Con todo, debe dejarse la puerta abierta a las rectificaciones puntuales de escaso alcance consistentes en evitar la partición municipal de edificaciones de cualquier tipo, mediante el desplazamiento de la linde a las calles inmediatas en el caso de tratarse de un entorno urbano.

\subsection{Pseudoenclaves}

Denominamos pseudoenclaves los apéndices de un término municipal que se encuentran unidos a la porción mayoritaria del término por un paso muy estrecho, de tal manera que, en función de la escala del mapa, el lector puede creer que se trata de auténticos enclaves. A efectos prácticos se trata de un enclave, y debería evitarse que la literalidad de la norma impida corregir estas situaciones. Es el caso de las dos protuberancias meridionales que presenta el término municipal de Guimerà (Figura 5), unidas al grueso del municipio por sendos pasillos que presentan una anchura mínima, que en la sección más estrecha no alcanza los $2 \mathrm{~m}$. Una corrección del epígrafe referido a las cuñas para incluir cualquier tipo de sinuosidades de la línea de término sería suficiente para acoger este supuesto.

Figura 5. Pseudoenclaves de Guimerà (Urgell)

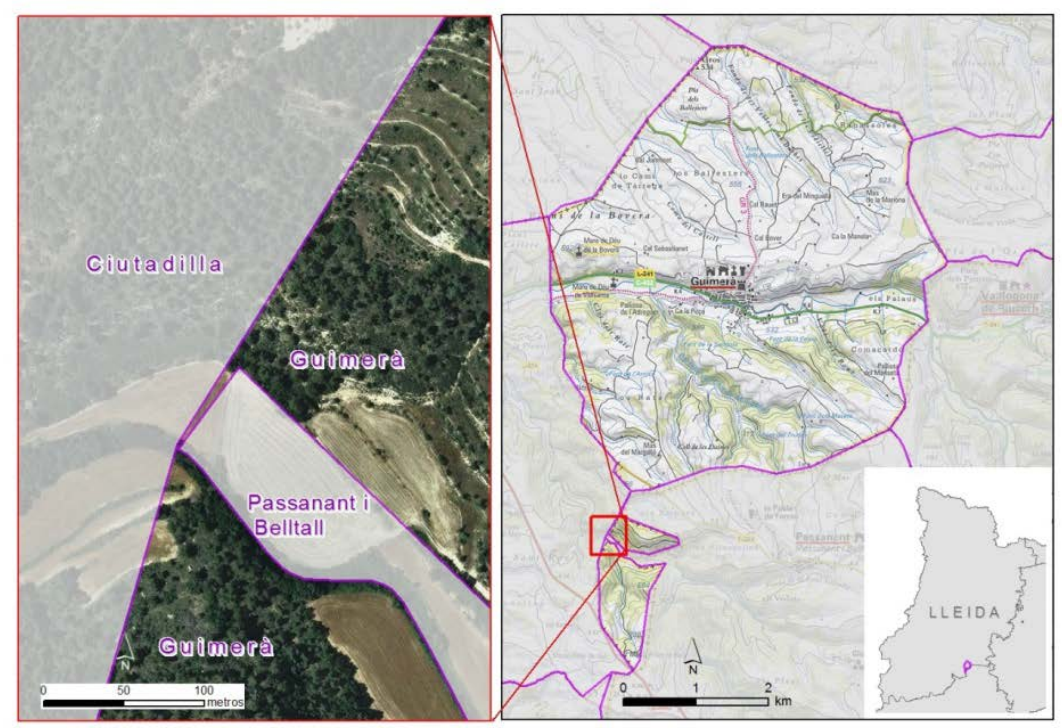

Fuente: elaboración propia a partir de la base cartográfica ICGC (2017) 


\subsection{Discordancia entre la delimitación municipal y la de un bien comunal}

En el Pirineo se conservan numerosos territorios comunales, es decir, cuya titularidad corresponde hoy a un ayuntamiento, EMD o comunidad de propietarios de origen comunal. Frecuentemente los límites de estos distritos no se ajustan a los municipales.

Generalmente la delimitación de los comunales es más fiable que la municipal descrita en los años 1920 a 1934 por los topógrafos del IGN. Así lo hemos comprobado en la comarca del Pallars Sobirà (Burgueño \& Mòdol, 2016). Los límites comunales generalmente gozan de mayor conocimiento y aceptación por parte de las comunidades locales que los municipales propiamente dichos, y a menudo, cuando se trata de un bosque incluido en el Catálogo de Utilidad Pública (CUP), su perímetro se ha amojonado más recientemente.

No obstante, también hay comunales mal delimitados o cuyo reconocimiento mimético como término municipal podría generar nuevas disfunciones, como por ejemplo nuevos enclaves. Por tanto, puede enunciarse la discrepancia entre ambos tipos de límites como una disfunción, pero debería acreditarse que la rectificación del término municipal implicará una mejora en la gestión del territorio.

\subsection{Condominios}

Aunque el ICGC no señala la existencia de ningún territorio municipal compartido en Cataluña, el MTN a escala 1:50 000 del IGN identifica claramente dos condominios en el Pirineo, ambos despoblados. Uno de ellos es muy pequeño (5 ha), lo comparten dos localidades adscritas a los municipios de Cava y El Pont de Bar (Alt Urgell). El otro es muy extenso $\left(22,5 \mathrm{~km}^{2}\right.$ según el cómputo del IGN y 23,7 km² según el CUP) y se conoce como la Mancomunitat dels Quatre Pobles, ya que es compartido por Esterri d'Àneu y otras tres localidades (Son, Sorpe y València d'Àneu) que hoy pertenecen al municipio de Alt Àneu (Pallars Sobirà) (Figura 6). Una investigación reciente sobre este condominio (Servei CT de Cartografia i SIG, 2017) demuestra que este ámbito compartido nunca ha sido suprimido, e incluso la Generalitat reconoció su pervivencia en un deslinde de 1993.

Estos condominios no son exactamente enclaves, ya que afrontan al menos con uno de los municipios poseedores. Parece razonable su agregación al municipio colindante, siempre y cuando esta decisión forme parte de un pacto entre los propietarios que asegure el cumplimiento del aprovechamiento común y que, por supuesto, no altere la titularidad compartida del bien.

Cabe añadir que en 2008 la CDT abordó el caso de un territorio singular, las islas Formigues (un pequeño archipiélago de la Costa Brava) que, a nuestro entender, debió ser considerado un condominio de Palamós y Palafrugell (Baix Empordà). Una concordia de 1717 establecía que dichas islas quedaran "comunas entre els dos pobles de Palamós y son comptat y Palafrugell y 
son terme, de tal manera que los uns ni altres de dits pobles pugan privar a l'altre de pescar ni fer altres cosas en ditas illas, sinó que, com dit és, aquellas sian comunas entre dits senyors y pobles respectivement". Finalmente la CDT se decantó por una solución salomónica: repartir los islotes entre ambos municipios.

\section{Figura 6. Término de la mancomunidad de los cuatro pueblos (Port de la Bonaigua)}

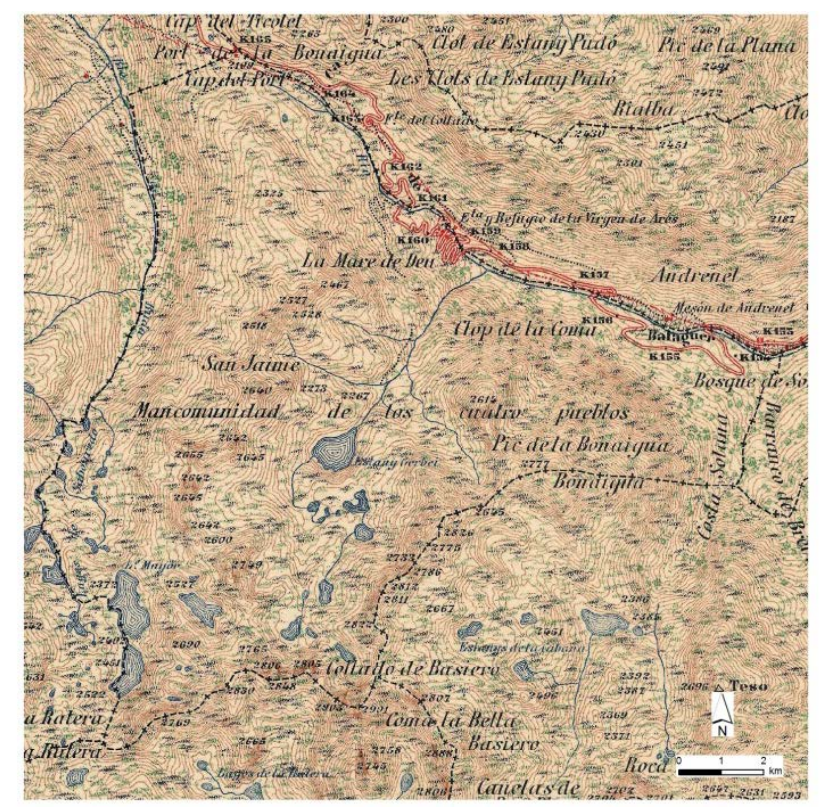

Fuente: elaboración propia a partir del IGN (1936), MTN 1:50.000, hoja 181

\subsection{Cuando el municipio es el enclave}

Los enclaves representan la disfunción territorial más evidente. Pero al igual que la totalidad de un municipio puede ser un enclave estatal, como sucede en el caso de Llívia (Cerdanya), también hay municipios cuya configuración territorial semeja la de un enclave o semienclave, ya que se encuentran en todo o en la mayor parte rodeados por un solo municipio. Este es el caso del pueblo de Sant Hipòlit de Voltregà (3429 hab.), cuyo pequeño término $\left(0,9 \mathrm{~km}^{2}\right)$ se encuentra completamente rodeado por Les Masies de Voltregà (3165 hab.), municipio rural originariamente, como su nombre indica. Resulta obvio que en un caso como este los dos municipios -campo y ciudad-constituyen una única realidad funcional. Es similar la situación enclavada de Roda de Ter en Les Masies de Roda (Osona), de Tremp en Talarn (Pallars Jussà), de Sant Llorenç de Morunys en Guixers y, en menor medida, de Solsona en Olius (los cuatro últimos municipios pertenecen al Solsonès).

Sin duda son disfunciones municipales, pero en un orden distinto, ya que afectan a la totalidad del municipio. Aunque las previsiones de la norma sobre disfunciones no sean aplicables en estos casos, entendemos que la situación geográfica constituye un argumento para que el legislador impulse medidas tales como la fusión de ambos municipios. 


\section{Conclusiones}

La legislación estatal señala como anomalía de la demarcación municipal los territorios que carecen de continuidad física con la porción principal de un término: los enclaves municipales. En este sentido, la Diputación foral de Bizkaia ha llevado a cabo un exhaustivo proceso de reordenación de límites municipales con objeto de erradicar todos los enclaves.

La legislación catalana es teóricamente más ambiciosa, porque no solo señala el problema de los enclaves sino que identifica la existencia de otros diversos aspectos disfuncionales en la demarcación municipal. Sin embargo, la existencia de un marco legal ad hoc y de un organismo consultivo (CDT) encargado de impulsar la corrección de esas disfunciones, prácticamente no ha dado lugar a ninguna actuación en los 30 años de vigencia de la normativa específica. Únicamente cabe destacar la resolución de una grave disfunción: la partición del núcleo de Sant Miquel de Balenyà entre tres municipios, pero de eso ya hace más de 20 años.

En realidad, casi siempre que se ha resuelto alguna que otra disfunción ha sido gracias al pacto de los propios ayuntamientos implicados, y mediante un proceso ordinario de alteración de límites. Puede afirmarse que la innovación jurídica no ha demostrado su utilidad por falta de iniciativa política. Bajo gobiernos autonómicos de signo político muy diferente, encabezando la Conselleria de Governació consellers de CiU, ERC y PSC, ninguno ha demostrado la menor intención de explorar y normalizar esta vía legal específica de Cataluña. En definitiva, la situación de Cataluña en lo que se refiere a la racionalización del mapa municipal resulta paradójica: tenemos legislación, existe procedimiento, se cuenta con una instancia promotora imparcial, pero lo que falta es voluntad política de acometer la tarea.

Por lo que se refiere a los supuestos de disfunciones identificados en la normativa, es necesaria una clarificación conceptual y una mejor definición de los supuestos, además de una cierta ampliación de los mismos. En el terreno de la clarificación, es urgente contar con una nómina objetiva de núcleos de población, ya que buena parte de los supuestos de disfunciones territoriales se refieren a ellos. En definitiva, un objetivo debería ser que cada núcleo de población estuviera adscrito al municipio más idóneo en atención a su ubicación geográfica.

Si no hay consenso entre las partes, la vía de alteración ordinaria es inadecuada en el caso de una disfunción territorial, como se demostró en el caso de Puigverd y Tornabous, ya que conviene que la iniciativa parta de un ente imparcial y objetivo (la CDT), sin intereses materiales en el territorio afectado.

Paradójicamente, pese a la inacción de la DGAL en la resolución de conflictos de límites, desplegó dos iniciativas aisladas de modificación de deslindes planteadas netamente al margen de la legalidad: un enclave provincial y un área de masías carente de núcleo de población. 
La corrección de disfunciones municipales, lejos de ser una operación de embellecimiento de la geometría jurisdiccional, debería ser una herramienta de racionalización de la gestión municipal y la prestación de servicios, así como una forma de simplificación de la vida cotidiana para los ciudadanos que residen en localidades con una problemática geopolítica derivada de su incómoda ubicación en relación a las líneas de término. La falta de actuación en situaciones de manifiesta disfuncionalidad, como la de un pueblo partido entre tres municipios, pone de manifiesto un serio fracaso político.

Agradecimientos: Proyecto de investigación CSO2017-87080-P (Ciudad y territorio en la cartografía española: una perspectiva histórica), del Ministerio de Ciencia, Innovación y Universidades.

Declaración responsable: Las/os autoras/es declaran que no existe ningún conflicto de interés en relación a la publicación de este artículo. En este artículo las/os autoras/es han realizado el texto conjuntamente. La elaboración de la cartografía ha sido a cargo de la autora Guerrero. 


\section{Bibliografía}

Burgueño, J., \& Gras, M. (2014). Atles de la Catalunya senyorial. Els ens locals en el canvi de règim (1800-1860). Barcelona: Institut Cartogràfic i Geològic de Catalunya.

Burgueño, J., \& Guerrero Lladós, M. (2014). El mapa municipal de España. Una caracterización geogràfica. Boletín de la Asociación de Geógrafos Españoles, 64, 11-36. Retrieved from http://www.boletinage.com/articulos/64/01_BURGUENO.pdf

Burgueño, J., \& Lasso de La Vega, F. (2002). Història del mapa municipal de Catalunya. Barcelona: Direcció General d’Administració Local.

Burgueño, J., \& Mòdol, J. (2016). Termes tradicionals dels pobles del Pallars Sobirà. In Béns comunals. Un sistema d'organització del passat per gestionar el present (pp. 61-105). Barcelona: Fundació del Món Rural y Institut per al Desenvolupament i la Promoció de l'Alt Pirineu i Aran.

Capdevila i Subirana, J. (2005). Els treballs de delimitació municipal del Instituto Geográfico Nacional a Catalunya, 1909-1930. Treballs de la Societat Catalana de Geografia, 60, 45-69.

Carnicer, R. (1995). Viaje a los enclaves españoles. Sabadell: Ausa.

Roca, M., Bonet, J., Burgueño, J., Casadevall, R., Font, T., Franquet, J... Cano, X. (2000). Informe sobre la revisió del model d'organització territorial de Catalunya. Barcelona: Departament de Governació i Relacions Institucionals. Retrieved from http://www.governslocals.cat/web/.content/Article/documentacio/2-organitzacio-governslocals/informe_OTC.pdf

Comissió Jurídica Assessora (2009). Dictamen 416/2009 Expedient de correcció de disfuncionalitats territorials dels municipis de Biosca, Torà (segarra) i Llobera (Solsonès) In Portal Jurídic de Catalunya. Retrieved from http://portaljuridic.gencat.cat/ca/pjur ocults/pjur resultats fitxa/?action=fitxa\&documentld= $\underline{689822 \& \text { language }=\text { ca_ES\&titleWords=tor\%25C3\%25A0\&mode }=\text { single }}$

Gallés i Cólera, P. (1985). Els enclavaments en el mapa municipal de Catalunya. Un cas d'estudi: el municipi de Tremp (MA dissertation, Universitat de Barcelona, Spain).

Generalitat de Catalunya (2018). Mapa municipal. In Municat. Retrieved from http://municat.gencat.cat/ca/Temes/El-mapa-municipal/mapa_municipal/

Guerrero i Lladós, M. (2013). Anàlisi geogràfica de les disfuncions territorials municipals a la província de Lleida mitjançant els SIG (Doctoral dissertation, Universitat de Lleida, Spain). Retrieved from http://www.tdx.cat/handle/10803/117141

Llista d'enclavaments a Catalunya (n.d.). In Wikipedia. Retrieved from https://ca.wikipedia.org/wiki/Llista_d'enclavaments_a_Catalunya 
López Trigal, L. (2013). Diccionario de geografía política y geopolítica. León: Universidad de León.

Masdeu, F., Jiménez, M., \& Ledo, R. (2015). La normalització de la delimitació municipal a Catalunya (2007-2015): una infraestructura bàsica per a la gestió territorial. Revista Catalana de Geografia, XX(52). Retrieved from http://www.rcg.cat/articles.php?id=342

Massó, J., \& Torres, M. (2009). La delimitació municipal a Catalunya. Revista Catalana de Geografia, XIV(37). Retrieved from http://www.rcg.cat/articles.php?id=161

Massó, J., Torres, M., \& Jiménez, M. (2011). La recuperació dels límits municipals històrics. Conveni DGAP-ICC (2005-2011). Revista Catalana de Geografia, XVI(43). Retrieved from http://www.rcg.cat/articles.php?id=212

Nadal, F., \& Urteaga, L. (2012). La delimitació dels termes municipals. In Atles topogràfic-històric de Catalunya 1:50.000. Primeres edicions dels fulls de Catalunya del Mapa Topográfico de España (pp. 41-44). Barcelona: Institut Cartogràfic de Catalunya.

Oliveras Samitier, J. (1997). Els límits municipals com a frontera. In J. Domingo \& L. Mallart (Eds.), A l'entorn de la frontera (pp. 53-70). Vilassar de Mar: Oikos-Tau.

Rebés i Solé, Josep-Enric (2009). Expediente de corrección de disfuncionalidades territoriales de los municipios de Biosca, Torà (Segarra) y Llobera (Solsonès) [DICTAMEN: 416/09, de 26 de noviembre]. Retrieved from http://portaldogc.gencat.cat/utilsEADOP/PDF/noDOGC/1416118.pdf

Rueda, I., Camarasa, J., \& Mateu, X. (1987). Diagnòstic del mapa municipal de Catalunya. Treballs de la Societat Catalana de Geografia, 10-11, 129-152.

Servei Cientificotècnic de Cartografia i Sig (2009). Estudi sobre la inexistència de raons geogràfiques que permetin i justifiquin la segregació d'un sector del nord del terme municipal de Torà (Segarra) per tal d'unir-lo a Llobera (Solsonès), atenent a la legislació municipal vigent (Informe inédito realizado para el Ayuntamiento de Torà). Lleida: Universitat de Lleida (Unpublished).

Servei Cientificotècnic de Cartografia i Sig (2016). Diagnosi geogràfica i socioeconòmica del nucli de la Beguda Alta per a la proposta de nova delimitació dels termes de Masquefa, Sant Esteve Sesrovires i Sant Llorenç d'Hortons. Lleida, Universitat de Lleida. Retrieved from http://www.masquefa.cat/uploads/Diagnosi-La-Beguda-Alta.pdf

Servei Cientificotècnic de Cartografia i Sig (2017). Informe sobre les forests mancomunals d'Esterri d'Àneu, Son, Sorpe i València d'Àneu (Pallars Sobirà) (Informe inédito realizado para el Ayuntamiento de Esterri d'Àneu). Lleida: Universitat de Lleida (Unpublished). 
Ticó i Duran, I., \& García Martínez, A. (1994). Recopilació de la documentació de delimitació municipal a Catalunya. Terra, 22, 28-38. 